\section{Thermo Fisher strides into gene therapy}

Thermo Fisher Scientific is set to buy viral vector manufacturer Brammer Bio for approximately $\$ 1.7$ billion, in a move that signals a foray into the gene-therapy field for the life sciences equipment maker. Brammer Bio, which makes viral vectors for use in in vivo and ex vivo gene-therapy clinical trials, was formed in 2016 by the merger of Brammer Biopharmaceuticals and Florida Biologix, a spin-out of the University of Florida. Thermo Fisher Scientific says it will incorporate the viral vector manufacturer, which employs almost 600 people, into its pharma services business. "Gene therapy is an area of increasing focus for our customers and is fast-evolving given its potential to treat a range of genetic disorders," said Thermo Fisher Scientific CEO Marc Casper in a 24 March press release announcing the deal. Thermo Fisher Scientific is no stranger to acquisitions: in 2014 it bought the Californiabased biotech Life Technologies for approximately $\$ 13.6$ billion, establishing it as a major player in the genetic testing field (Nat. Biotechnol. 31, 573-574, 2013). Biotech giants are fast snapping up gene-therapy startups. In February, the Swiss pharma giant Roche acquired Spark Therapeutics, the Children's Hospital of Philadelphia startup, whose gene therapy to treat an inherited retinal disease won FDA approval in 2017. And in March, Cambridge, Massachusettsbased Biogen acquired London-based biotech Nightstar Therapeutics, which is also developing gene therapies for inherited retinal diseases.

Published online: 3 May 2019

https://doi.org/10.1038/s41587-019-0132-0

\section{Spark's meteoric rise from hospital-funded spinout to $\$ 4.8$ billion deal}

\author{
Roche vows to retain gene therapy leader's culture.
}

$\wedge$ pediatric hospital spinout responsible for bringing to market in the United States the first gene therapy for treating an inherited disease has been acquired by Swiss pharmaceutical giant Roche. Spark Therapeutics, the Children's Hospital of Philadelphia startup, in 2017 received US Food and Drug Administration approval for Luxturna (voretigene of retinal dystrophy (Nat. Biotechnol. 36, 6, 2018). The February 25 deal values the fiveand-a-half year-old Spark at $\$ 4.8$ billion, more than twice the company's market valuation before the announcement. Baselbased Roche will keep its target at arm's length in an attempt to preserve what made it an attractive target in the first place, saying that Spark will continue to operate as an independent gene therapy specialist out of its Philadelphia headquarters.

Also on March 4, Biogen acquired Nightstar Therapeutics, a London-based biotech developing gene therapies for rare inherited retinal diseases, for $\$ 800$ million. neparvovec-rzyl) to treat an inherited form
This and the Spark deal underscore large companies 'growing appetite for gene therapies, as well as ophthalmic indications' prominence as an early proving ground for these technologies.

With the Spark buyout, Roche gains US rights to Luxturna. The therapy replaces the mutated RPE65, a gene encoding the enzyme retinoid isomerohydrolase in the retina, which transduces light into electrical signals. Luxturna recorded \$27 million in revenue in its first year on the US market. But Roche's real prize is Spark's gene therapy pipeline-in particular, a pair of treatments for hemophilia A, the most advanced of which should enter phase 3 this year. (Novartis already holds non-US rights to Luxturna and Spark's hemophilia B program is partnered, with Pfizer; Table 1.)

This blood-disorders market is one where Roche has already carved out a lucrative niche: its Hemlibra (emicizumab-kxwh) humanized IgG4 monoclonal antibody for hemophilia A has been a key growth driver

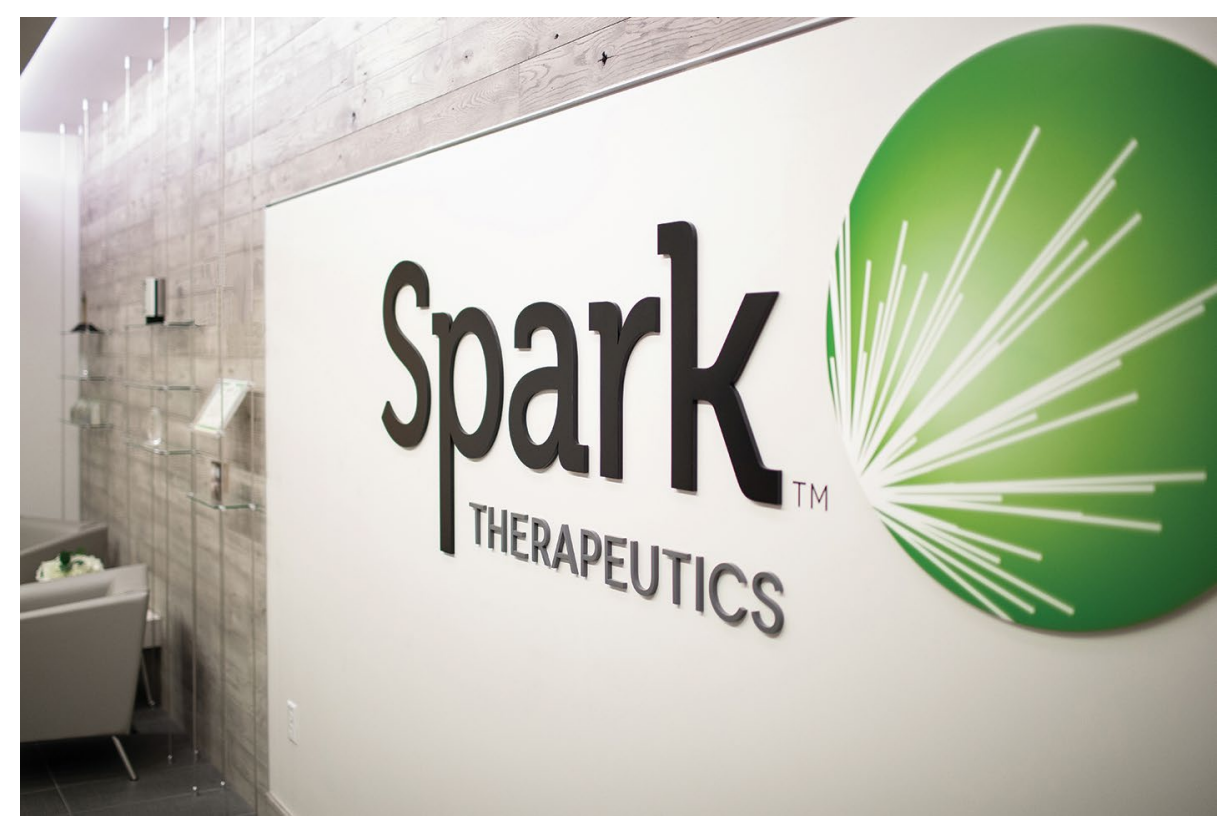

Roche's acquisition of gene therapy developer Spark Therapeutics, founded by researchers from Children's Hospital of Philadelphia, will result in a huge return on the hospital's initial investment. Credit: Spark Therapeutics. 